\title{
A SENTENCE TO LIFE
}

\section{Pet project.}

\section{BY IGOR TEPER}

$\mathrm{B}$ etter to be dead.

Sitting on a park bench, watching the swans scribe their inscrutable trajectories on the lake's surface, streams of joggers, dog walkers, families with strollers flowing around him, but never too close, Julius felt more alone than ever. Better to be dead.

He knew he couldn't blame Tabytha, could only blame himself, but the whole thing was just so outrageous. If she hadn't broken his heart, then stomped on it; hadn't made him feel so betrayed and humiliated, he never would have posted all those detailed descriptions of meals consisting of boiled, broiled, braised, baked, grilled, poached, sautéed and stewed crow on the site where she documented her meals. He never would have posted exhaustive, fawning reviews of every film in the Passion of the Zombie Vampire heptalogy on the site where she logged her media consumption. He never would have replaced all her profile photos with selections from the ratemylooks.com all-time bottom-20 and updated her relationship status to 'putrescing.

Doing it, he'd been gleeful and self-satisfied, even euphoric - but, afterwards, he'd felt even worse than before, as if anticipating the price he'd pay. Was now paying.

With cybercrime overtaking fleshcrime in annual costs; with cybercriminals capable, through self-replicating agent programs, of being in an unlimited number of places at once; with prisons overflowing, the Cybercrime Act of 2032 had been overdetermined. The digitization of life that had made cyberbanishment meaningful had also made it inevitable.

Cyberbanishment: the deletion of all his cyberaccounts and, far worse, the deactivation of his arfid and his arfreader. Sitting there, in the park, he was surrounded by people, but, to him, they were faceless ciphers, with no names, no interests, no relationships, none of the scores of personal details that their arfids were broadcasting for everyone else's arfreaders to project onto their retinas. And, to them, he was an ersatz person, revealing nothing and thus capable of anything. Even the dogs, with their mandated arfids, were fuller members of society than him.

For several hours, Julius had tried to make eye contact with someone, with anyone, but people's eyes just passed over him, as if he were an inanimate part of the landscape.

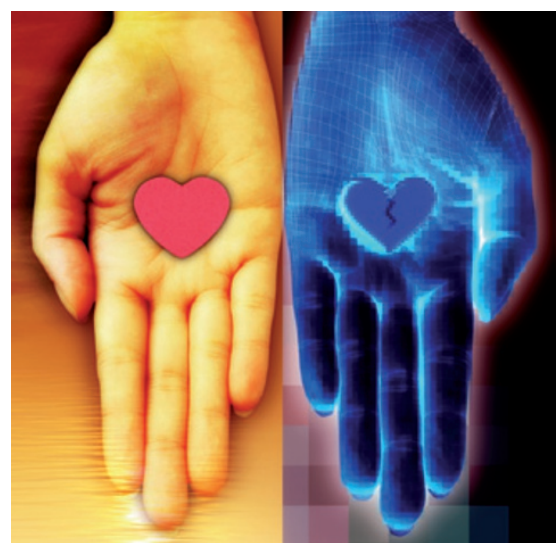

The most he got, at least from adults, were several double takes as people saw him, then, worried that their arfreader was malfunctioning, looked at someone else, and, reassured, glanced, very quickly, back at him. Dogs and small children with no arfreaders did look at him, but their alarmed guardians quickly steered them away.

He reminded himself that he'd lived with no arfreader until his twelfth birthday, but it was one thing to have never experienced the world's true contextual richness, and a very much worse thing to have lost it.

"It's only for a year," he told himself.

"A whole year!" his despondent self retorted.

In a year, his friends would have forgotten him twice over, half his vocabulary would be out of date, the entire culture would have passed him by.

He closed his eyes, and squeezed his fingers into fists. As he tried to recapture, in his mind, the world he'd lost, something wet brushed over his left wrist.

He opened his eyes - a dog, a golden retriever, was licking the back of his hand. Seized by conflicting impulses of gratitude to the dog for acknowledging him and alarm at being so unceremoniously licked by a strange animal, Julius froze.

"Don't worry - he only does that to people he likes," said a woman's voice.

Approaching, looking straight at him: short, athletic, dark-skinned, darker-haired - perhaps Indian - and ... that was all he knew about her, which is to say he knew nothing. He couldn't remember the last time

$\rightarrow$ NATURE.COM

Follow Futures on

Facebook at:

go.nature.com/mtoodm he'd conversed with a complete stranger.

Disarming anxiety bloomed in the pit of his stomach. He fought it back, aware of the irony, and forced himself to focus on her, now just an arm's length away, with his unaugmented sight. Her face was freckled, and pretty.

"I'm Rometa," she said, and offered her hand.

"I'm Julius." As he extended his hand, he was painfully aware that his palm was soaked with sweat.

When they shook, only the softest alarm went off in the back of his head - he didn't know her vaccination status. Then again, her dog had already licked him.

"You must really love dogs," she said.

"Why do you say that?"

"Well, you didn't recoil from him even though he's ..." she glanced around, then whispered, "illegal." When she saw the confusion on his face, she raised her eyebrows and added: "No arfid."

He smiled, tasting bitterness.

"That makes two of us," he said.

Now it was her turn to look confused.

"I've been, um, cyberbanished," he said. "Couldn't you tell?"

"I keep my arfreader off most of the time," she said. "Banished, huh? Must be quite a story."

"You keep it off? By choice?"

"To you, that must seem like choosing to live in a prison."

"How do you interact, with people?"

"I talk, I listen, I pay attention. If I want to know something about someone, I just ask."

"But how do you know if you can trust people?"

"I've learned that I usually can. Besides, Shakespeare here is a better judge of character than any arfreader will ever be. Aren't you, boy?"

She bent down and ran her hand over the dog's neck and shoulders, then back around to its throat and chin. The dog smiled and licked her open palm.

"I just can't believe it," Julius said, shaking his head.

"Come on our walk," Rometa said, "and I'll show you a thing or two about this prison called real life."

As he jogged after her into the great unknown mysterious world, Julius felt something he hadn't in a long time. Anticipation.

Igor Teper lives with his wife and son in the San Francisco Bay Area and teaches old atoms new tricks at temperatures near absolute zero. He also writes stories, occasionally. 